\title{
Tradução da introdução do liuro Wissenschaft als kunst de Paul Feyerabend
}

Profa. Dra.

Cristina de Amorim Machado UEM

cristina_machado@yahoo.com

Recebido em 11/02/17

Aceito em 13/02/17

Para citar este artigo: MACHADO, Cristina de Amorim. Tradução da introdução do livro Wissenschaft als Kunst de Paul Feyerabend. Em Construção. ano 1, n. 1, 2017, pp. 152-156. DOI:10.12957/ emconstrucao.2017.28129

\section{Apresentação}

\begin{abstract}
Esse movimento [contra a crença clássica na razão iluminista] completou sua obra - ou então ainda não a concluiu, porque sua continuação necessária é a reconstituição da razão humana sobre uma nova base, a conquista de um conceito de humanismo que ganhe profundidade em comparação com o conceito superficial e autocomplacente da era burguesa.
\end{abstract}

Thomas Mann, Pensadores modernos, p. 269

É difícil falar de Paul Karl Feyerabend (1924-1994) sem despertar amor ou ódio pelos mais diversos motivos. Sua língua ferina, seu estilo polêmico e sua crítica à hegemonia da tradição científica causaram alguns problemas na recepção dos seus textos. O lema "ame-o ou deixe-o" parece se ajustar bem a esse caso, como se pode ver no título do livro The worst enemy of science? Essays in memory of Paul Feyerabend (Preston; Munévar; Lamb, 2000). Nesta pequena apresentação ficarei com a primeira parte da disjunção, não porque se trate de um elogio apaixonado a esse filósofo, mas porque acredito que o encontro com suas ideias é sempre inspirador, uma potente contribuição para a filosofia, as ciências e a sociedade em geral.

A obra de Feyerabend inclui vários livros, artigos, entre outras produções, e foi publicada originalmente em alemão e inglês, incluindo, em alguns casos, revisão e autotradução (tradução realizada pelo próprio autor), às vezes com consideráveis modificações. Ademais, ele traduziu para o alemão os dois volumes do livro The open society and its enemies, de Karl Popper (1952), e o clássico livro Criticism 
and the growth of knowledge, organizado por Imre Lakatos e Alan Musgrave (1970), fruto de um colóquio de filosofia da ciência realizado em 1965, conhecidos entre nós, respectivamente, como A sociedade aberta $e$ seus inimigos e A crítica e o desenvolvimento do conhecimento.

Dos seus livros mais conhecidos, somente a primeira edição de Contra o método, traduzida para o português por Octanny da Motta e Leonidas Hegenberg em 1977, e também a sua autobiografia - Matando o tempo -, traduzida por Raul Fiker em 1996, foram traduzidas no calor da hora, dois anos depois da publicação dos respectivos originais. A terceira edição de Contra o método (1993) e alguns outros - Ciência em uma sociedade livre (1978), Adeus à razão (1987) e o póstumo Conquista da abundância (1999) - foram publicados em português só nos últimos 10 anos.

Em 2001 foi publicado no Brasil o livro Diálogos sobre o conhecimento, traduzido por Gita Guinsburg. Escritos originalmente em inglês em 1991, esses diálogos foram traduzidos e publicados no mesmo ano em italiano, edição da qual derivou a tradução brasileira. Agora em 2016 saiu um novo livro de Feyerabend, Ciência, um monstro - lições trentinas, que é a tradução de Rogério Bettoni da versão italiana de uma série de conferências sem título ministradas por Feyerabend em Trento, na Itália, no início de maio de 1992. ${ }^{1}$ A transcrição das fitas foi revisada pelo próprio Feyerabend, traduzida para o italiano e publicada em 1996. Dessa edição se origina a tradução brasileira, que foi revisada e anotada por Luiz Henrique Abrahão. O material original foi publicado em inglês com outro título, The tyranny of Science, em 2011, sob coordenação de Eric Oberheim.

Além desses livros, Feyerabend escreveu alguns outros menos conhecidos entre os seus leitores luso -brasileiros, como o Wissenschaft als Kunst [Ciência como arte], publicado originalmente em 1984, portanto entre Ciência em uma sociedade livre e Adeus à razão. Alguns capítulos do livro já apareceram traduzidos em inglês e italiano, mas nunca foi feita nenhuma tradução para o português.

Vale lembrar que a arte sempre foi um interesse de Feyerabend, que estudou canto, teatro (foi convidado para ser um dos assistentes de produção de Bertold Brecht) e chegou a fazer uma ponta no filme Der Prozess, de G. W. Pabst (1948). Ele sempre pensou a relação entre ciência e arte, e isso influenciou diretamente a sua vida prática e também as suas concepções filosóficas pluralistas, como se pode ver em toda a sua obra. Só para citar um exemplo da terceira edição de Contra o método (Feyerabend, 2007, p. 357):

As artes, como as vejo atualmente, não constituem um domínio separado do pensamento abstrato, mas complementar a ele, e precisavam realizar plenamente seu potencial. Examinar essa função das artes e tentar estabelecer um modo de pesquisa que una seu poder com o da ciência e o da religião parece-me ser um empreendimento fascinante, ao qual eu poderia dedicar um ano (ou dois, ou três...).

Pena que ele não viveria tanto tempo mais...

Como veremos na introdução traduzida a seguir, o livro se divide em seis capítulos, dos quais os quatro primeiros são frutos de uma série de conferências realizadas por Feyerabend em Zurique no início dos anos 1980. São eles: 1) Ciência como arte; 2) Progresso na arte, na filosofia e na ciência; 3) Criatividade - fundamento das ciências e das artes ou conversa fiada?; 4) Concepções holística e agregacionista exemplificadas pela continuidade e pelo movimento; 5) Conhecimento para a sobrevivência; e 6) São as ciências instituições de pesquisa ou partidos políticos?

1 Isto é o que diz o copyright; porém, na "Nota da edição brasileira" (p. 37), o leitor é informado de que a tradução foi feita com base no texto datilografado em inglês e que, da edição italiana, foram traduzidas só as notas. Um dos anexos também foi traduzido do italiano, mas ele é exclusivo da edição brasileira. 


\section{Ciência como arte}

\section{Introdução}

Os capítulos de 1 a 4 deste livro se baseiam em palestras e seminários que eu proferi de 1981 a 1983 na Universidade Técnica Suíça (Eidgenössischen Technischen Hochschule - ETH) em Zurique.

O primeiro capítulo é uma versão ampliada da minha palestra inaugural. Para essa palestra eu fui enganado por meio de uma pequena travessura do então reitor da ETH. Ele me avisou que a palestra seria paga e pediu que eu informasse a data e o título dela. Eu perguntei se a palestra era parte das minhas obrigações e ainda acrescentei que, caso contrário, eu não a faria; mas, de qualquer modo, indiquei uma data e um título. "Muito obrigado", dizia a resposta, "nós agendamos a palestra na data que o senhor propôs - e ela não é obrigatória". Durante a palestra, apesar da minha estridente exposição, o bom senhor reitor dormia o sono dos justos. Também o título e o conteúdo são antes o resultado de um acidente do que de um plano consciente. $\mathrm{Na}$ época do convite visitei muitas livrarias e também li a maioria dos catálogos das editoras - o que eu faço uma vez por ano, todo ano. Na época da palestra, pensei em títulos engenhosos como "Racionalidade e sensibilidade", "Ciência e religião", "Arte e razão" etc. "Eu quero irritar um pouco esses sérios senhores" - eu falei comigo mesmo - "por que não um título do tipo 'Ciência como arte'?". "Ademais", assim continuava o diálogo com os meus botões, "a palestra resultará em nada de qualquer jeito". Eu me iludi e tinha agora a tarefa de fornecer o conteúdo da hipótese do título. Não achei isso difícil, porque há muito tempo eu já tinha a suspeita de que as claras divisões das especialidades que nos são feitas por filósofos e sociólogos, e também por muitos especialistas, que as consideram corretas e essenciais tanto nas artes quanto nas ciências, não correspondem de jeito algum à prática dessas especialidades. Nem as ciências fornecem a unidade conceitual que frequentemente lhes é conferida, e da qual se deriva sua grande autoridade estatal, nem é a diversidade das práticas, com a qual se compõe o campo das ciências, tão distintamente separada de outras áreas, como poderia sugerir a ideia de uma diferença substancial entre as ciências e as artes. Mesmo com a ideia de uma transição gradual, a situação é descrita de maneira bastante incompleta. Não há campos que sejam "puramente científicos" e outros que nada mais são que "arte pura", com uma área entre eles na qual as duas coisas se misturam, mas sim procedimentos artísticos que ocorrem por todo lado nas ciências e sobretudo lá onde se têm feito descobertas surpreendentes. Como explicar essa estranha situação e que tanta gente inteligente continue apoiando a ideia de uma clara divisão?

A explicação (que eu desenvolverei detalhadamente num livro posterior) é mais ou menos assim: todas as especialidades eram inicialmente "artes" (technai em grego), ou seja, elas se diferenciavam de fato por seus resultados (a arte da navegação era diferente da arte da cura, que era diferente da arte do bom discurso), não por seus métodos - as pessoas reuniam experiências, organizavam-nas tão bem quanto possível e depois estabeleciam discípulos com elas. As experiências não eram só de tipo conceitual, elas também consistiam do conhecimento direto dos sintomas (do tempo, de uma doença), isto é, as pessoas não podiam "objetivá -las" e separá-las do processo de aprendizado da prática à qual pertenciam. Os filósofos gregos, sobretudo Platão, trouxeram novas exigências para as especialidades: não basta que essas especialidades tenham resultados, elas também devem ser obtidas do modo correto, e isso significa que elas devem ser formuláveis conceitualmente, e que o conceito deve ser adequado a regras gerais (da lógica, da argumentação). É muito difícil dizer como essas exigências quase irrealistas ganharam corpo e logo se tornaram o fundamento para todas as pesquisas - no quarto capítulo eu forneço uma breve explicação para isso. Com certeza, uma delas é a seguinte: as exigências logo enfrentaram dificuldades e foram criticadas. O resultado da crítica não foi o desaparecimento das exigências, mas um tipo de divisão do trabalho: a pesquisa, como de costume, era adequada aos velhos procedimentos, aumentados pelas novas descobertas que eram feitas constantemente. As exigências, no entanto, definiram o discurso sobre a pesquisa ou, como também se poderia dizer, a ideo-

2 Esta tradução só foi possível graças à revisão cuidadosa de Adriano Steffler, a quem agradeço também pelas aulas de alemão e pela parceria nas minhas aventuras pela língua de Goethe. 
logia da pesquisa. Naturalmente, a ideologia também tinha influência na própria pesquisa, não em seu tipo estritamente imposto, mas de modo mais casual e "subjetivo", da mesma maneira que ideias influenciam uma arte. A história dessa mistura de procedimentos realistas e exigências irrealistas oferece um espetáculo fascinante, mas foi examinado com poucos detalhes até agora.

Os capítulos de 2 a 4 são versões ampliadas de pequenos artigos que eu apresentei em meu seminário vespertino, toda quinta-feira das cinco às sete horas no auditório F7. O segundo capítulo se relaciona diretamente com a palestra inaugural. $\mathrm{O}$ terceiro capítulo critica a tendência muito popular atualmente de resolver os problemas do conhecimento e da arte por meio da evidência de "habilidades criativas" que nunca foram descritas em detalhes, e tenta mostrar que a "invenção audaciosa de hipóteses" nas ciências tem um papel menor do que certos mitólogos da ciência nos querem fazer crer. O quarto capítulo comenta as discussões sem fim da teoria das cores de Goethe. A controvérsia entre Goethe e Newton é esclarecida frequentemente por meio da controvérsia entre intuição e matemática. Eu afirmo que uma controvérsia similar já ocorre na matemática pura.

A semelhança entre as artes e as ciências aparece no último capítulo de um modo um pouco diferente: nem as artes nem as ciências conhecem os critérios estáveis que limitam a atividade de seus adeptos o tempo todo com uma autoridade além da mera opinião; nem as ciências nem as artes nos podem dizer de modo inquestionavelmente científico ou artístico para onde é direcionada uma determinada ideia ou método. É claro que os especialistas fazem constantemente tais previsões e de fato com maior precisão, mas a história de suas especialidades mostra que eles não obedecem ao processo do desenvolvimento real de seus princípios, $\mathrm{e}$ sim que transformam esses princípios em slogans ou dogmas. É claro que eles podem fazer isso - mas então deixam de ser especialistas e se tornam cidadãos comuns, e sua autoridade não é maior do que a dos cidadãos comuns: decisões científicas e artísticas essenciais são por natureza decisões, que devem ser tomadas de modo democrático. O último capítulo esclarece especificamente por que deve ser assim.

Agora é muito importante ver como nosso conhecimento é transformado por meio de uma completa democratização das ciências e das artes. A concepção usual é a seguinte: as pessoas aprendem a conhecer e controlar as coisas pensando sobre elas. Pensar sobre as coisas significa criar teorias sobre as coisas e verificar de acordo com as regras de manipulação de teorias. Pensar sobre as pessoas, portanto, também significa criar teorias sobre as pessoas e verificar de acordo com as regras de manipulação de teorias. O pensamento e a criação de teorias são as tarefas de determinadas profissões, sobretudo as dos intelectuais. Crises conduzem a uma controvérsia dos intelectuais e a uma variedade de teorias. Não é a sociedade como um todo o fórum em que as crises são discutidas e as soluções propostas, mas sim modelos abstratos dela que estão sujeitos ao domínio de um pequeno grupo de especialistas. Não são pessoas animadas com sua rica subjetividade que seguem esses modelos, mas sim caricaturas delas, como "o trabalhador", "o economista", "o artista", "o cientista". Não são os objetos das caricaturas que decidem sobre sua utilidade, mas sim os construtores, notadamente segundo princípios sobre os quais o resto da humanidade com suas vontades e sonhos, como sempre, não tem influência. Então aconteceu que se entregou a solução dos problemas predominantes não às pessoas que eram afetadas por eles e cuja sensibilidade era altamente desenvolvida por meio da confrontação contínua com os problemas, mas sim a especialistas, e também eles não perguntaram às pessoas envolvidas, mas sim projetaram mais teorias com mais caricaturas. Muita gente na Europa e nos Estados Unidos é hoje contra uma intensificação da política de confrontação atômica existente, uma maioria persiste numa estabilização - mas suas opiniões são ignoradas por especialistas, políticos, teóricos de jogos, economistas, pelos cientistas que servem à aniquilação (cerca de um terço de todos os cientistas desse mundo). Isto não é culpa só dos políticos - é culpa de uma velha tradição de conhecimento "objetivo", isto é, separado das vontades, dos sentimentos e das noções das pessoas mais simples. Democratização significa que a aliança entre teorias e pessoas não ocorre num desvio por outras teorias nas quais as pessoas só aparecem como entidades teóricas, ou seja, caricaturas; mas sim que as pessoas afetam diretamente as teorias, definindo, por meio do voto ou um consenso democrático, a expansão e a aplicação das teorias. Esta também é uma velha tradição (cf. o fim da Oréstia, de Ésquilo), que corresponde à ideia de uma sociedade livre, mas que também está em harmonia com os fatos que nós podemos aprender com a história de grandes descobertas científicas. O último capítulo menciona alguns desses fatos. 
Assim eu chego finalmente ao breve quinto capítulo. Trata-se do resultado do meu encontro com Grazia Borrini, uma gentil, adorável, mas muito determinada guerreira pela paz. De modo ingênuo, já estou comprometido democraticamente há muito tempo. Há tempos, eu me enfureço, quando vejo com que ignorância arrogante muitos intelectuais deixam de lado noções que não combinam com seus planos, embora forneçam conteúdo e segurança à vida de muita gente. Milhares de acadêmicos desprezíveis recebem com prazer seus gordos salários, sem se dar ao trabalho de agradecer, sem um sentimento de gratidão para com aqueles que lhes depositam sua confiança, sem um senso de perspectiva.

Eu estava bem preparado, quando Grazia trouxe para o primeiro plano essa questão da perspectiva mas sobre as minhas próprias prioridades eu ainda não tinha consciência. Grazia me trouxe essa clareza. Qual é o problema mais importante em nosso tempo? O problema da paz em suas mais variadas formas - a paz com nossos semelhantes, mesmo que eles tenham opinião diferente; da paz com outras nações, mesmo que com isso esteja associada a admissão de grandes erros; e o problema da paz com a natureza, mesmo que isso signifique que nós não mais consideremos a natureza como nossa escrava, e sim como uma parceira de vida com direitos iguais. Muitas causas contribuíram para a origem desse problema - uma delas é o hiato entre natureza e humanidade, e instituição e humanidade, que surge como consequência de uma concepção "objetiva" e não democrática da natureza do nosso conhecimento. A democratização das artes e das ciências diminui o hiato, nos aproxima da solução do problema da paz em todos os seus aspectos e corresponde também à "dinâmica interna" das grandes descobertas científicas (que eu mostro novamente no sexto capítulo). Encontram-se, portanto, várias ideias e tendências num ponto, que, contudo, deveria ter estado claro já desse o princípio - na atenção para com o indivíduo, suas vontades, seus sentimentos e seu mundo subjetivo.

\section{Referências bibliográficas}

FEYERABEND, Paul Karl. Wissenschaft als kunst. Frankfurt am Main: Editora Suhrkamp, 2013 [1984].

. Ciência, um monstro - lições trentinas. Edição, revisão técnica e notas de Luiz Henrique Abrahão. Tradução de Rogério Bettoni. Belo Horizonte: Autêntica Editora, 2016.

. The tyranny of science. Edição e introdução de Eric Oberheim. Cambridge: Polity Press, 2011.

_. A ciência em uma sociedade livre. Tradução de Vera Joscelyne. São Paulo: Unesp, 2011 [1978].

_. Adeus à razão. Tradução de Vera Joscelyne. São Paulo: Unesp, 2010 [1987].

. Contra o método. 3a . edição. Tradução de Cezar Augusto Mortari. São Paulo: Editora Unesp, 2007 [1993].

. A conquista da abundância. Tradução de Cecilia Prada e Marcelo Rouanet. São Leopoldo/RS: Editora Unisinos, 2006 [1999].

. Diálogos sobre o conhecimento. Tradução de Gita K. Guinsburg. São Paulo: Editora Perspectiva, 2001.

_. Matando o tempo: uma autobiografia. Tradução de Raul Fiker. São Paulo: Editora UNESP, 1996.

. Contra o método. $1^{a}$. edição. Tradução de Octanny da Motta e Leonidas Hegenberg. Rio de Janeiro: Editora Francisco Alves, 1977.

LAKATOS, Imre; MUSGRAVE, Alan. (Orgs.). Criticism and the growth of knowledge. London: Cambridge University Press, 1970.

MANN, Thomas. Pensadores modernos: Freud, Nietzsche, Wagner e Schopenhauer. Tradução de Márcio Suzuki. Rio de Janeiro: Editora Zahar, 2005.

PABST, Georg Wilhelm. Der Prozess. Österricheische Wochenschau und Filmproduktion, 1948.

POPPER, Karl. The open society and its enemies. Vols. 1 e 2. Londres: Routledge and Kegan Paul, 1952.

PRESTON, John; MUNÉVAR, Gonzalo; LAMB, David. The worst enemy of science? Essays in memory of Paul Feyerabend. NY/Oxford: Oxford University Press, 2000. 